\title{
Penyusunan Sistem Pengembangan Karyawan Melalui Pelatihan dengan Pendekatan Appreciative Inquiry
}

\author{
EDWARSYAH $^{1 *}$, SEGER HANDOYO ${ }^{2}, \&$ MARIA EKO SULISTYOWATI ${ }^{1}$ \\ 1 Program Studi Magister Psikologi Terapan, Fakultas Psikologi Universitas Airlangga \& 2 Departemen \\ Psikologi Industri dan Organisasi, Fakultas Psikologi Universitas Airlangga
}

\begin{abstract}
ABSTRAK
Salah satu tantangan terbesar dalam industri minyak dan gas bumi di sektor hulu adalah kegiatan eksplorasi dan eksploitasi migas yang berkelanjutan untuk menjaga agar lapangan tetap berproduksi. Kegiatan eksplorasi dan produksi yang berhasil tidak terlepas dari kemampuan dan pengelolaan sumber daya manusia yang dimiliki oleh perusahaan. Perusahaan membutuhkan tenaga kerja yang profesional dan memiliki kualifikasi tinggi dalam mengelola kegiatan usaha hulu migas yang memiliki karakteristik padat modal, padat risiko, dan padat teknologi. Penelitian ini dilakukan dengan tujuan untuk menyusun sistim pengembangan karyawan melalui pelatihan dengan pendekatan appreciative inquiry. Penelitian ini menggunakan metode kualitatif menggunakan tahapan 4D appreciative inquiry. Hasil penelitian menunjukkan bahwa pendekatan appreciative inquiry dapat mengeluarkan kekuatan dan nilai positif yang ada dalam organisasi, dan membuat komitmen dari organisasi untuk melakukan yang lebih baik lagi dalam hal pelatihan dan pengembangan karyawan.
\end{abstract}

Kata kunci: appreciative inquiry, pelatihan dan pengembangan karyawan

\begin{abstract}
One of the biggest challenges in the oil and gas industry in the upstream sector is sustainable of oil and gas exploration and exploitation activities to keep the field in productive. Successful exploration and production activities cannot be separated from the ability and management of human resources in the company. The company requires professional and high qualified workforce in managing upstream oil and gas business activities that have characteristics of high capital, risk and technology intensives. This research was conducted with the aim of compiling an employee development system through training with the appreciative inquiry approach. The research method is qualitative using the stages of 4D appreciative inquiry. The results showed that the appreciative inquiry approach could bring out the positive strengths and core-values that exist within the organization and make a commitment from the organization to do better in terms of employees training and development.
\end{abstract}

Keywords: appreciative inquiry, employee training and development 
INSAN Jurnal Psikologi dan Kesehatan Mental, 2019, Vol. 4(2), 102-110, doi: 10.20473/jpkm.v4i22019.102-110 Dikirimkan: 28 November 2019 Diterima: 25 Januari Diterbitkan: 2 April 2020

Editor: Dewi Syarifah

*Alamat korespondensi: Fakultas Psikologi Universitas Airlangga, Jalan Airlangga 4-6 Surabaya 60286. Pos-el: edwarsyah@sakaenergi.com

Naskah ini merupakan naskah dengan akses terbuka dibawah ketentuan the Creative Common Attribution License (http://creativecommons.org/licenses/by/4.0), sehingga penggunaan, distribusi, reproduksi dalam media apapun atas artikel ini tidak dibatasi, selama sumber aslinya disitir dengan baik.

\section{P E N D A H U L U A N}

Eksplorasi merupakan salah satu tahapan penting dalam kegiatan usaha hulu minyak dan gas bumi (migas). Cadangan migas baru tidak akan bisa ditemukan tanpa adanya kegiatan eksplorasi, baik di wilayah kerja migas yang sudah berproduksi maupun di kawasan yang sama sekali belum tersentuh. Keberhasilan kegiatan eksplorasi dan produksi migas tidak terlepas dari kemampuan sumber daya manusia yang dimiliki oleh perusahaan. Mengingat pentingnya industri migas dalam teknologi dunia modern sekarang ini, peran pekerja dengan kompetensi tinggi sangat penting dalam mencapai tujuan strategis perusahaan migas (Jamshidi, Rasli, \& Yusof, 2012). Perusahaan migas harus memiliki tenaga kerja yang profesional dan memiliki kualifikasi tinggi dalam mengelola kegiatan usaha hulu migas yang memiliki karakteristik padat modal, padat risiko, dan padat teknologi. Edwin (2015) menyatakan bahwa investasi pada sumber daya manusia menjadi sangat penting bagi industri migas untuk mengoperasikan teknologi yang semakin maju dan menjaga perusahaan tetap produktif dan kompetitif.

PT. SIPL sebagai sebuah perusahaan swasta nasional yang bergerak di bidang eksplorasi dan produksi migas di Indonesia terus menerus melakukan pengembangan lapangan produksinya yang tentu saja membutuhkan karyawan yang memiliki kompetensi tinggi. PT. SIPL menganut mekanisme pengembangan karyawan seperti yang di jabarkan dalam buku peraturan perusahaan (company regulation) tentang pengembangan karyawan. Pengembangan tersebut dilakukan dalam bentuk mutasi, promosi, pendidikan dan pelatihan karyawan. Pengembangan karyawan melalui mekanisme pelatihan memberikan kesempatan yang luas kepada karyawan untuk mengikuti program-program pelatihan yang diselenggarakan oleh perusahaan, baik yang diselenggarakan sendiri oleh perusahaan, maupun mengikuti pelatihan yang diselenggarakan secara publik.

Pelatihan yang diselenggarakan oleh perusahaan mencakup pelatihan-pelatihan untuk pengembangan individu karyawan (individual development), pelatihan teknis (technical training), maupun pelatihan wajib (mandatory training) yang berhubungan dengan pemenuhan peraturan pemerintah maupun pemenuhan persyaratan kebijakan HSE (Health, Safey and Environmental). Pada tahun 2014 sampai 2016, rata-rata pemyelenggaraan program pelatihan mencapai angka 108 jam pelatihan (manhour) untuk setiap karyawan. Jumlah manhour tersebut cukup tinggi dibandingkan dengan manhour pelatihan pada standar industri di Amerika yang rata-rata hanya mencapai 43,8 jam pelatihan per karyawan (Trainingmag, 2016). Sementara Noe \& Kodwani (2018) menyebutkan bahwa rata-rata manhour karyawan yang mengikuti pelatihan secara formal adalah 31,5 jam.

Jumlah manhour pelatihan yang cukup tinggi di PT. SIPL seharusnya menunjukkan bahwa kegiatan pelatihan karyawan dilaksanakan dengan perencanaan dan agenda yang sangat baik. Akan tetapi pada data penyelanggaraan pelatihan tahun 2016 menunjukkan bahwa hanya 41 persen manhour pelatihan yang dilaksanakan berdasarkan program pelatihan yang telah direncanakan sebelumnya (berdasarkan 
training plan). Sedangkan 59 persen manhour pelatihan terlaksana tanpa adanya perencanaan program pelatihan sebelumnya (unplanned training).

Pelatihan yang tidak terencana (unplanned training) terjadi dikarenakan permasalahan peralatan (shutdown/troubleshoot); karyawan cenderung bersifat responsif dan reaktif terhadap tawaran dari pihak penyelenggara pelatihan publik, sehingga kemudian mengikuti pelatihan tanpa perencanaan; karyawan mengikuti perintah atasan untuk mengikuti pelatihan tertentu atau mengikuti pelatihan wajib (mandatory training) yang tidak berhubungan langsung dengan bidang pekerjaannya; dan kegiatan analisa kebutuhan training (Training Needs Analysis, TNA) belum dilakukan secara menyeluruh untuk mengidentifikasi pelatihan apa saja yang dibutuhkan oleh karyawan.

Kegiatan pelatihan yang baik dimulai dari proses perencanaan, pelaksanaan, sampai pada proses evaluasi terhadap program pelatihan tersebut. Noe \& Kodwani (2018) menjelaskan sebuah pendekatan sistematis dalam perencanaan dan pelaksanaan program pelatihan yang efektif yang terdiri dari 7 tahapan yang teridri dari melakukan penilaian kebutuhan pelatihan, mempersiapkan karyawan untuk mengikuti pelatihan, kemudian membuat situasi pembelajaran yang sesuai dengan kebutuhan, memastikan terjadinya proses pembelajaran, membuat rencana evaluasi, memlilih metode pelaksanaan pelatihan, dan melakukan evaluasi atas program pelatihan serta melakukan perubahan program pelatihan jika diperlukan.

Peneliti melihat bahwa pelaksanaan kegiatan pengembangan karyawan dalam bentuk pelatihan di PT. SIPL belum menggambarkan pelaksanaan kegiatan pelatihan yang sistematis seperti yang dijelaskan oleh Noe \& Kodwani (2018). Salah satu pendekatan yang digunakan dalam sistem pelatihan dan pengembangan karyawan, pengembangan manajemen dan organisasi, pengembangan tim, serta perubahan budaya adalah dengan metode Appreciative Inquiry (Cooperrider, Whitney, Stavros, \& Stavros, 2008). Appreciative Inquiry (AI) adalah sebuah studi tentang mendapatkan hal-hal terbaik dalam diri manusia. Pendekatan ini dapat digunakan untuk perubahan pribadi dan perubahan organisasi yang didasarkan pada anggapan bahwa pertanyaan-pertanyaan positif dan dialog tentang kekuatan, keberhasilan, nilai-nilai, harapan dan mimpi merupakan transformasi dari diri mereka sendiri untuk mecapai keberhasilan yang diinginkan (Whitney \& Trosten-Bloom, 2010).

Dalam konteks pengembangan individu dan organisasi, Watson (2013) menerapkan metode AI dalam pengembangan para manajer di lembaga pendidikan lanjutan dan pendidikan tinggi di Inggris. AI di gunakan untuk menemukan proses yang tepat bagi pengembangan para manajer, dan menjamin bahwa prioritas pengembangan tersebut sejalan dengan prioritas strategis dari setiap lembaga pendidikan tersebut. Hasil penelitian Watson ini menyimpulkan bahwa AI dapat menghasilkan tingkat keterlibatan yang tinggi pada seluruh populasi manajemen dan mempercepat pengembangan hubungan, motivasi dan pemecahan masalah yang inovatif.

Abadi (2014) dalam penelitiannya menggunakan metode AI dalam upaya meningkatkan kapasitas dan kapabilitas organisasi di bidang perencanaan dan pengembangan Pusdiklat Pajak. Hasil penelitiannya menunjukkan bahwa penerapan metode AI telah membawa perubahan ke arah yang lebih baik dalam perencanaan dan strategi pengembangan di Pusdiklat Pajak, serta seluruh karyawan berpartisipasi secara aktif menumbuhkan perasaan senang, bangga, dan termotivasi untuk melakukan perubahan dalam rangka mencapai keadaan yang diimpikan.

Penerapan pendekatan AI dalam rujukan dan penelitian tersebut di atas menunjukkan bahwa prinsip utama AI yang konstruktif untuk membangun masa depan, membangun kesadaran dengan kata-kata atau pertanyaan yang positif, serta keterlibatan dalam mewujudkan impian bersama dapat meningkatkan kemampuan dalam organisasi. Merujuk pada kekuatan pendekatan AI tersebut, Peneliti melihat bahwa pendekatan AI dapat diterapkan dalam upaya penyusunan pengembangan karyawan melalui sistem pelatihan di PT. SIPL.

INSAN Jurnal Psikologi dan Kesehatan Mental

2019, Vol. 4(2), 102-110

doi: $10.20473 /$ jpkm.v4i22019.102-110 
Berdasarkan pemaparan di atas, penelitian ini dilakukan bertujuan untuk menerapkan pendekatan AI dalam menggali potensi pengembangan dan menyusun sistem pengembangan karyawan melalui pelatihan agar dapat dihasilkan sebuah sistem pengembangan melalui pelatihan karyawan yang efektif, proaktif dan antisipatif, sehingga dapat di terapkan dalam pengelolaan pelatihan perusahaan di masa depan.

\section{E T O D E}

\section{Desain Penelitian}

Penelitian ini dilakukan dengan menggunakan metode kualitatif dengan menggunakan tahapan 4D AI sebagai alat untuk melakukan pengambilan data. Data diperoleh dengan teknik wawancara pada tahapan Discovery dan Dream, dan teknik focus group discussion pada tahapan Design dan Destiny.

\section{Partisipan}

Partisipan pada penelitian ini adalah karyawan dari departemen Operations dan Supporting departemen sebanyak 12 partisipan. Pemilihan partisipan di dasarkan pada keterlibatan mereka dalam proses pengembangan karyawan, dimana partisipan memiliki jabatan yang berpengaruh terhadap kegiatan pengembangan dan pelatihan karyawan di departemen masing-masing. Selain itu partisipan juga memiliki masa kerja di perusahaan lebih dari lima tahun, sehingga memiliki wawasan terhadap topik penelitian ini

\section{Analisis Data}

Analisis data yang digunakan adalah transkip hasil wawancara, reduksi dan kategorisasi data, analisis tema dan terfokus, dan interpretasi data.

\section{HAS IL PENELITIAN}

\section{Intervensi AI Discovery dan Dream}

Intervensi tahap Discovery untuk menggali dan mendapatkan gambaran mengenai kekuatan positif apa saja yang ada di PT. SIPL secara umum dan yang berhubungan dengan topik penelitian ini. Hasil intervensi tahap ini menunjukkan bahwa terdapat empat tema utama tentang kekuatan positif yang muncul dari hasil wawancara, yaitu: (1) SIPL sebagai rumah kita semua, (2) Aset perusahaan yang terus berkembang, (3) Dukungan komitmen dan anggaran pelatihan, dan (4) Pengembangan diri dan karir.

Intervensi tahap Dream untuk menggali impian, harapan dan keinginan partisipan terhadap perusahaan, program pengembangan dan pelatihan karyawan yang ideal di masa depan. Peneliti menemukan bahwa pada tahapan Dream, para partisipan memimpikan aset perusahaan menjadi lebih besar lagi bahkan sampai di tingkat internasional, dan para karyawan diharapkan untuk memiliki pengetahuan dan keahlian yang lebih baik lagi seiring dengan perkembangan perusahaan. Impian dan harapan partisipan dalam tahap Dream ini menjadi sebuah pernyataan provokatif (provocative proposition) dengan tema "Karyawan yang professional untuk membangun aset kebanggaan nasional". Whitney \& Trosten-Bloom (2010) menjelaskan bahwa pernyataan provokatif adalah sebuah pernyataan yang menggambarkan suatu keadaan atau organisasi yang ideal, atau "apa yang seharusnya ada". Pernyataan ini sebagai jembatan dari kekuatan yang sudah ada (Discovery) dengan impian apa yang mungkin terjadi (Dream) sehingga nantinya didapatkan rangkaian tindakan (Design). 


\section{Intervensi AI Design dan Destiny}

Intervensi tahap ini untuk untuk mendapatkan elemen-elemen rancangan, rencana tindakan, dan komitmen dari para partisipan terhadap hasil dari intervensi tahap pertama. Intervensi tahap Design menghasilkan empat topik rancangan dalam sistim pelatihan, yaitu (1) Orientasi karyawan, (2) Pengembangan karyawan, (3) Training needs analysis, dan (4) Evaluasi pelatihan.

Sistem pelatihan yang disusun ditunjukkan pada Gambar 1 berikut.

\begin{tabular}{|c|c|c|c|c|}
\hline \multicolumn{5}{|c|}{ Evaluation } \\
\hline $\begin{array}{c}\text { Specialized HSE } \\
\text { Topics }\end{array}$ & $\begin{array}{l}\text { Specialized Technical } \\
\text { Operations }\end{array}$ & $\begin{array}{l}\text { Specialized Technical } \\
\text { Maintenance }\end{array}$ & & \\
\hline $\begin{array}{l}\text { HSE Management } \\
\text { System }\end{array}$ & LPG Processing & Utilities & & \\
\hline Emergency Response & Oil Treatment Facility & $\begin{array}{l}\text { Rotating \& Static } \\
\text { Equipments }\end{array}$ & & \\
\hline Observation Card & Gas Processing & $\begin{array}{l}\text { Turbomachinery } \\
\text { Equipments }\end{array}$ & $\begin{array}{c}\text { Work Program \& } \\
\text { Budget }\end{array}$ & Supervisory Skills \\
\hline H2S Awareness & \multicolumn{2}{|c|}{ Instrumentation \& Process Control } & $\begin{array}{l}\text { Basic Exploration \& } \\
\text { Petroleum Engineering }\end{array}$ & $\begin{array}{l}\text { Problem Solving \& } \\
\text { Decision Making }\end{array}$ \\
\hline $\begin{array}{c}\text { Personal Protective } \\
\text { Equipment }\end{array}$ & \multicolumn{2}{|c|}{ Offshore Operations \& Maintenance Overview } & $\begin{array}{c}\text { Introduction to Oil \& } \\
\text { Gas }\end{array}$ & Teamwork \\
\hline HSE Orientation & \multicolumn{2}{|c|}{ Onshore Operations \& Maintenance Overview } & $\begin{array}{c}\text { Production Sharing } \\
\text { Contract }\end{array}$ & Communication Skill \\
\hline $\begin{array}{c}\text { Health, Safety \& } \\
\text { Environment (HSE) }\end{array}$ & $\begin{array}{l}\text { Basic Technical } \\
\text { Production }\end{array}$ & $\begin{array}{l}\text { Basic Technical } \\
\text { Maintenance }\end{array}$ & $\begin{array}{c}\text { Basic Oil \& Gas } \\
\text { Business }\end{array}$ & Softkills \\
\hline \multicolumn{5}{|c|}{ Pelatihan Karyawan } \\
\hline \multicolumn{5}{|c|}{ Orientasi Karyawan } \\
\hline
\end{tabular}

Gambar 1. Sistem pelatihan karyawan

\section{I S K U S I}

\section{Proses AI dalam Penelitian}

Penggunaan AI sebagai sebuah pendekatan untuk melibatkan peserta dalam proses menemukan dan menghasilkan kemungkinan-kemungkinan yang terbaik bagi masa depan telah ditunjukkan dalam berbagai konteks. Penggalian informasi dari pengalaman positif dan hal yang terbaik dari para partisipan akan menghasilkan pernyataan-pernyataan yang membawa pada keinginan dan harapan agar perusahaan dan pengembangan karyawan menjadi lebih baik lagi (Whitney \& Trosten-Bloom, 2010)

Pendekatan AI dalam menggali dan menemukan pengalaman-pengalaman terbaik para partisipan dalam penelitian ini menghasilkan pernyataan-pernyataan yang sangat positif, seperti yang ditemukan pada tahapan Discovery, dimana dirangkum bahwa para partisipan merasa bahwa perusahaan memiliki kekuatan sebagai "rumah" bagi karyawan, kemudian karyawan memandang positif dengan aset perusahaan yang terus berkembang, serta kekuatan dari dukungan komitmen dan anggaran pelatihan yang cukup besar, serta pelatihan yang mendukung pengembangan karir.

Pernyataan yang menunjukkan kekuatan tersebut sangat konstruktif, positif dan membawa harapan yang lebih baik lagi ke depannya. Hal ini sesuai dengan prinsip-prinsip dalam AI seperti yang dijelaskan 
oleh Whitney \& Trosten-Bloom (2010), bahwa AI antara lain memiliki prinsip konstruktif, positif, dan berlaku keseluruhan.

Pada tahapan wawancara Discovery, seorang partisipan menyampaikan pernyataan puitis tentang impiannya: "Kepompong menjadi kupu-kupu yang indah, kupu-kupu yang terbang dipandang banyak orang, menyenangkan orang yang melihatnya".

Sementara partisipan lainnya SHM menceritakan impiannya tentang perusahaan menjadi seperti matahari yang terus bersinar menerangi bumi. Pada siang hari, matahari memberikan energi cahayanya untuk menerangi bumi secara langsung. Dan pada malam hari, matahari memberikan energi melalui bulan agar bercahaya menerangi bumi.

Pernyataan yang bersifat puitis ini menggambarkan impian para partisipan tentang sebuah keadaan yang mereka inginkan pada perusahaan. Impian yang bersifat perumpamaan ini sesuai dengan salah satu prinsip AI, yaitu prinsip puitis (Whitney \& Trosten-Bloom, 2010), dimana partisipan menggunakan kata-kata yang bebas dan universal untuk menggambarkan impian mereka tentang perusahaan di masa depan. Kekuatan prinsip puitis tersebut diyakini akan menjadi energi untuk bersama-sama diwujudkan bagi keberhasilan perusahaan. Johnson \& Leavitt (2001) menjelaskan bahwa AI didasarkan keyakinan pada kekuatan afirmasi, dimana jika kita dapat membayangkan apa yang kita inginkan, maka keinginan tersebut akan menjadi kenyataan.

Selama proses AI berlangsung, para partisipan sangat terbuka untuk menceritakan kisah dan pengalaman mereka, berbicara secara terbuka, memberikan informasi yang mereka ketahui, bahkan tanpa ada rasa sungkan sama sekali. Hal ini menunjukkan bahwa dalam pelaksanaan intervensi para partisipan memiliki kebebasan untuk menentukan sikap dan pernyataannya. Dalam AI, prinsip ini sesuai dengan prinsip bebas memilih untuk menentukan kontribusinya masing-masing.

\section{Sistem Pelatihan Karyawan}

Penggunaan pendekatan AI untuk menyusun sistem pengembangan karyawan melalui pelatihan dalam penelitian ini menghasilkan sebuah proses pengembangan karyawan yang dimulai dari mekanisme orientasi karyawan baru yang secara terus-menerus harus dievaluasi dan ditingkatkan kualitasnya, kemudian dilanjutkan dengan program pelatihan yang sesuai dengan kebutuhan karyawan di setiap departemen.

Sistem pelatihan karyawan yang berhasil disusun mencakup tiga hal utama, yaitu:

1. Orientasi karyawan, yaitu kegiatan bagi karyawan baru untuk memberikan bekal pengetahuan umum tentang perusahaan, departemen terkait dan ruang lingkup bisnis prosesnya;

2. Kegiatan pelatihan, yaitu pelatihan bagi karyawan yang mencakup topik HSE, basic-specialized technical production, basic-specialized technical maintenance, basic oil and gas business, dan soft skills;

3. Evaluasi, untuk menilai sejauh mana karyawan mendapatkan pengetahuan dan keahlian dari program-program pelatihan yang telah dilakukan, dan penilaian terhadap potensi karyawan untuk pengembangan karirnya.

Penyusunan sistem pelatihan karyawan ini merupakan gabungan dari keterampilan dasar (basic skills), keterampilan teknis (hard skills) dan non-teknis (soft skills) yang sangat dibutuhkan dalam industri migas agar karyawan dapat mengoperasikan teknologi yang semakin maju, serta untuk tetap produktif dan kompetitif. Sistem pelatihan ini dimaksudkan juga untuk mengantisipasi agar karyawan terampil di segala bidang dan dapat berkembang dengan cepat. Edwin (2015) menjelaskan bahwa pada banyak industri sangat dibutuhkan keterampilan teknis, soft skills dan manajerial. Jamshidi dkk. (2012) 
menyatakan bahwa keterampilan non-teknis (soft skills) memberikan kontibusi yang tinggi terhadap kinerja perusahaan dalam mencapai misi dan tujuan strategisnya.

Hal penting lainnya dalam sistem pengembangan karyawan adalah mekanisme evaluasi terhadap proses dan hasil pelatihan. Saat ini evaluasi pelatihan yang telah dilakukan di PT. SIPL mengikuti metode Kirkpatrick, yaitu baru pada tingkatan reaksi (Reaction) dengan mengisi formulir evaluasi setelah mengikuti pelatihan, dan tingkatan pembelajaran (Learning) melalui pre-test dan post-test. Dari hasil FGD, partisipan mengharapkan agar evaluasi ini dapat dilakukan pada tingkatan penilaian perilaku (Behavior) dan penerapan keahlian karyawan di tempat kerja setelah mengikuti pelatihan.

\section{Penerapan Tindakan dan Evaluasi Intervensi}

Penerapan tindakan intervensi AI merupakan implementasi dari topik rancangan yang telah disusun pada tahapan Design. Topik rancangan yang telah di terapkan di PT. SIPL selama periode tahun 2018 adalah; (1) penyusunan jadwal pelatihan internal (in-house training calendar); (2) penyusunan technical competency profile untuk departemen Operations; (3) penyelenggaraan pelatihan umum dan teknis tentang proses bisnis di aset lain; dan (4) pelaksanaan evaluasi pelatihan.

Evaluasi intervensi AI dilakukan untuk melihat sejauh mana intervensi telah dilakukan dan apa saja tindakan yang dapat dilakukan untuk perbaikan selanjutnya. Coghlan (2019) menyatakan bahwa evaluasi terhadap program intervensi merupakan bagian yang sangat penting untuk mengetahui apakah tindakan yang diambil sudah benar, tindakan diambil dengan cara yang sesuai, dan sebagai masukkan untuk perencanaan dan tindakan selanjutnya. Cooperrider dkk. (2008) menjelaskan bahwa tujuan dari tahapan Destiny adalah untuk memastikan bahwa mimpi (Dream) dapat diwujudkan. Tahapan Destiny ini mewakili kesimpulan dari tahapan Discovery, Dream, dan Design, serta merupakan awal terbentuknya budaya belajar yang apresiatif.

Hasil tahapan evaluasi dari program intervensi menghasilkan komitmen untuk perbaikan dan tindakan selanjutnya tentang empat hal berikut ini:

1. Perbaikan sistem training calendar dan identifikasi peserta pelatihan agar lebih tepat sasaran sesuai dengan bidang pekerjaan dan posisi karyawan;

2. Perbaikan profil kompetensi agar lebih detail sesuai dengan kondisi peralatan dan proses yang ada di lapangan. Kemudian dilakukan competency assessment oleh pihak ketiga (konsultan) agar hasilnya lebih obyektif, dan selanjutnya hasil assessment dapat digunakan sebagai dasar TNA;

3. Pembuatan online training library yang terintegrasi dengan metode $e$-learning, termasuk pembuatan modul-modul pelatihan dasar sebagai hasil dari TNA setelah competency assessment dilakukan;

4. Evaluasi pelatihan dilakukan sampai pada penerapan pengetahuan dan keahlian di tempat kerja (behaviour).

\section{S I M P U L A N}

Hasil penelitian menunjukkan bahwa pendekatan AI berhasil dilakukan dalam upaya penyusunan sistem pengembangan karyawan melalui pelatihan. Pada tahapan Discovery menghasilkan empat tema utama, yaitu SIPL sebagai rumah kita semua, aset perusahaan yang terus berkembang, kekuatan dukungan komitmen dan anggaran pelatihan, dan pelatihan mendukung pengembangan diri dan karir karyawan. Pada tahapan Dream, partisipan memimpikan aset perusahaan menjadi lebih besar sampai tingkat internasional, dan para karyawan harus memiliki pengetahuan dan keahlian yang lebih baik lagi seiring dengan perkembangan perusahaan. Pada tahapan Design menghasilkan elemen rancangan sistem pelatihan yang mencakup aspek sistem orientasi karyawan, struktur pelatihan (HSE, teknis, dan 
non-teknis), dan evaluasi program pelatihan dan pengembangan karyawan. Kemudian pada tahapan Destiny menghasilkan komitmen untuk perbaikan dan peningkatan training calendar, competency profile, evaluasi pelatihan, serta usulan pembuatan online training library dan e-learning.

Pelaksanaan AI diikuti oleh partisipan dengan antusiasme yang tinggi dan partisipasi yang aktif. Pendekatan AI telah berhasil dilakukan dalam penelitian ini dengan hadirnya prinsip-prinsip AI, seperti prinsip konstruktif, positif, puitif dan berlaku keseluruhan.

Untuk penelitian selanjutnya disarankan agar proses AI dilakukan dalam lingkup yang lebih besar di organisasi PT. SIPL, dengan melibatkan karyawan di lokasi kerja yang lain. Adapun sistem pelatihan dan pengembangan karyawan yang telah disusun perlu ditingkatkan dan dikaji lebih jauh untuk mengantisipasi perkembangan perusahaan dan masukan dari lini manajemen.

\section{U C A P A N T ERIMAKASIH}

Penulis mengucapkan terima kasih kepada seluruh partisipan yang telah bersedia meluangkan waktunya dan bersedia terlibat dalam penelitian ini.

\section{DEKLARASI POTENSI TERJADINYAKONFLIK KEPENTINGAN}

Edwarsyah, Seger Handoyo, dan Maria Eko Setyowati tidak bekerja, menjadi konsultan, memiliki saham, atau menerima dana dari perusahaan atau organisasi manapun yang mungkin akan mengambil untung dari diterbitkannya naskah ini.

\section{PUSTAKA ACUAN}

Abadi, I. (2014). Appreciative inquiry untuk peningkatan kapasitas dan kapabilitas organisasi di bidang renbang pusdiklat pajak. Universitas Airlangga.

Coghlan, D. (2019). Doing action research in your own organization. SAGE Publications Limited.

Cooperrider, D., Whitney, D. D., Stavros, J. M., \& Stavros, J. (2008). The appreciative inquiry handbook: For leaders of change. Berrett-Koehler Publishers.

Edwin, A. (2015). Training and development in the Oil and Gas Industry. Journal of Business Administration and Management Sciences Research, 4(9), 197-207.

Jamshidi, M. H. M., Rasli, A., \& Yusof, R. (2012). Essential competencies for the supervisors of oil and gas industrial companies. Procedia-Social and Behavioral Sciences, 40, 368-374.

Johnson, G., \& Leavitt, W. (2001). Building on success: Transforming organizations through an appreciative inquiry. Public Personnel Management, 30(1), 129-136.

Noe, R. A., \& Kodwani, A. D. (2018). Employee Training and Development (7th ed.). McGraw-Hill Education.

Trainingmag. (2016). Training industry report 2016. Retrieved from https://trainingmag.com/sites/default/files/images/Training_Industry_Report_2016.pdf.

INSAN Jurnal Psikologi dan Kesehatan Mental

2019, Vol. 4(2), 102-110

doi: 10.20473/jpkm.v4i22019.102-110 
Watson, S. (2013). Who owns the gap? (Part one): Appreciative Inquiry as a diagnostic tool. Industrial and Commercial Training.

Whitney, D. D., \& Trosten-Bloom, A. (2010). The power of appreciative inquiry: A practical guide to positive change. San Fransisco: Berrett-Koehler Publishers. 